\title{
$[6]$
}

\section{The Absence of Others, the Presence of Texts}

\author{
Don Handelman
}

In Memory of Henry Moses Rupert (c. 1885-1973)

A few years ago a friend passed on to me photocopies of a small corpus of fieldnotes on Washo shamanism that were collected during the early 1920s by Grace Dangberg. ${ }^{1}$ Grace Dangberg, a pioneer of Washo ethnology, will be remembered for her published translations of Washo myths and tales. Of special interest to me were the notes that described the beliefs and attitudes of a man with whom I had spoken at some length during the summer of 1964. Henry Moses Rupert was a gifted person, a healer, and a fine teacher of the solvents of reality. Tucked among Dangberg's fieldnotes were two unpublished fragments that read very much like separate beginnings of accounts of her experiences of Henry Rupert. Both postdated 1967, the year in which I had first published a biographical article about him.

These fragments, one in particular, led me to think off and on about three varieties of the absence of the Other and their influences on ethnography and writing. The first of these absences is that of the voice of the native Other in ethnographic texts. Much discussed today, it is of some relevance to why the second variety of absence became important to me in relation to Henry Rupert. This second is the native at home, with his or her memories of absent anthropologists, who themselves are absent from their own texts that are based (or based in part) on information the native supplied. The ethnographer absent 


\section{Don Handelman}

from his or her own text refers to objectivist modes of reporting. The third variety of absence is that of our own voices (our oral or informally written professional discourses) from one another's texts. This is so commonplace and common-sensical that it is quite ignored. Yet, this third variety of absence should push us to question our own cultural assumptions about the discipline of anthropology, not so much as an intellectual and aesthetic endeavor, but as an enterprise of individual careers that are identified with the ownership of the authorship of knowledge. This necessarily is a hierarchical pattern that obviates any significant place for dialogue within the text and is exemplified in the very logic of construction, of the packaging, of the ethnographic text.

The first variety of absence has pride of place today in discussions on the construction of ethnography. It has made more explicit, and rendered problematic, the status, the authority, and the authenticity of the native as Other, the object as subject, and the space that is made in texts for his or her voice, for the other's authorship of self, in counterpoint to ours of him or her. The absence of the native Other is redressed in degree through constructions that are called interpretive (Little 1980), dialogical (Tedlock 1979; Dwyer 1982), and polyphonic (Clifford 1983).

The second variety of absence is buried in particular contexts of field experience, and it rarely surfaces within ethnographic texts (but cf. Pandey 1972). This variety relates to the native as interpreter of ethnographers and as mediator of their imaginary discourse. It seems to be restricted to situations in which the native becomes the authoritative reporter on the contacts with ethnographers who had spoken with him or her in the past, for an ethnographer who is present but who cannot find the voices of these others in their own texts. The native and the ethnographer are then in a dialogue that is somewhat akin to discussions about a native Other who is absent. But here the Other at issue is the ethnographer, absent from his or her own text.

The third variety of absence is a shadowy complement of the first, although its absent Other seems much closer to home than the one who dwells and thinks elsewhere. The absence of this Other is cloaked by the treatment of him or her as "another," one more like you and me, one of the same kind. This sort of absence is structured rigidly by the logical strictures of book, monograph, and article. It is hedged in by conventions of writing, by mutual respect (and at times by fear), and by the very idea of "career" that many of us hold and that includes 
the "copyrights" to knowledge upon which the personal enterprise depends.

Though the voice of this third absent Other is muted and circumscribed in ethnographic writing, it influences no less than the native Other the ways in which the text is put together. I am referring, of course, to how we affect one another's writings, to how we do not insert one another's voices into the texts we construct, and to the structure of conventions of the "ownership" of knowledge that virtually demands our absence from one another's works. Certainly, we are active voices to one another, often in dialogue: yet, the narrow spaces we make for one another, indeed that we are permitted to make, bear a strong resemblance to those made for the natives in classical ethnography. Our capacities for usufruct speedily threaten the rights of others to the ownership of knowledge, and may quickly deteriorate into dark cries about stolen "ideas" and murmured mutterings about plagiarism, not to mention claims made to informants, ethnic groupings, whole communities, and even, in my experience, to entire cities with tens of thousands of inhabitants. So here the Other at issue is the ethnographer who is absent from the texts of others, who themselves are dominated by the privatized career and by the hierarchical logic of the structuring of the scholarly text.

Hermeneutic, dialogic, and polyphonic approaches to ethnographic construction broaden and deepen our uncertainty about, and thus our empathy with, that Other who lives out there, on our horizons. We still like to see ourselves standing alone, nearing that Other on the frontiers of comprehension, between worlds. Or so it seems. For this romantic image, as it appears explicitly or implicitly in innumerable ethnographies, effectively blocks from view the substrata of hinterland and home. Our conceit in deconstructing the myth of classical ethnographic authority (in James Clifford's phrasing) has enabled us to hold to the fiction that our relationships with one another are less relevant to how texts are constructed, and to the hegemonies over knowledge and expertise that such texts proclaim. There are excellent institutional and instrumental reasons for this state of affairs, but this does not make it any less so. If we cannot radically inlay the voices of other ethnographers in our own texts, and I question the likelihood of this, then I doubt the success of doing the same for the voice of the native Other. ${ }^{2}$ For, structurally, each is a logical extension of the other. Therefore, their estrangement, which we continue to foster, 
enables us to hide from ourselves the relevance of those premises about the ownership of the text upon which our careers, in large measure, depend.

Let me begin with how I came to recognize that there was an Other out there, with my trained naiveté, and with how Mr. Rupert and I came to talk to each other.

\section{Who's Out There? The Voice of the Other}

Before I met him, Henry Rupert had had contacts with (to my knowledge) six other ethnographers. To some he confided in detail about his beliefs and powers. Others he kept more at arm's length. Before approaching Mr. Rupert I was told that, for a period, he had made himself unavailable to ethnographers. Why was not clear. But, I was informed, he might be having a change of mind. Through the generosity of his eldest son and his daughter-in-law I was able to live close by, to try to engage him on what I had defined as the topic of healing.

I came to that place in the desert of Nevada with two significant typifications, "shaman" and "culture," which were part of assorted baggage acquired as a student. "The shaman," I understood from my readings and from discussions with peers and professors, was a cultural role or persona whose incumbents did society's work of healing illness, fending off witches, and reducing anxiety, individual and collective, in certain kinds of cultures. This cultural role, I had learned, was one of many that an individual played, switching back-and-forth according to the dictates of value, norm, and situation. So Rupert, I thought, would be sometimes a shaman, and at other times would put this role aside in order to perform those other roles of his repertoire. I also thought that the objective typification, of SHAMAN, was what his information would signify. Once his information had filled this slot, the typification then would signify him, the person, made over in its image. These roles were part of tradition, and tradition part of CULTURE, in this instance Washo culture. Therefore, one step further along, the typification would signify something about Washo culture that, in turn, would signify a place within itself for the typification of WASHO SHAMAN. In my text-to-come the typifications, my constructions and those of my discipline, would have pride of place. Rupert was a means to these ends. 
We met almost daily, usually in the afternoon, seated on rickety chairs under a tree, shaded from the sun's blaze. From him I collected word lists, trait lists, information on aboriginal seasonal rounds, on myth and game, on hunting and fishing, and so forth. Now and then I would ask about power, healing, spirits, dreams, and the character of the afterlife. Aside from some information that he insisted was held by many Washo (as it was), he denied any special knowledge or ability. "I'm just a common man," he would reiterate, pursing his lips, "I don't know anything about these things." These intermittent interchanges continued for days.

One evening he stopped by my tent and asked whether I ever had let my imagination run loose. Tense with anticipation, I replied that I had. He told of the time, when a young man, he had gone fishing in a creek in the hills. He started for home just before sundown. Walking along the trail in the dim light of the forest he saw something white by a clump of trees, blocking his route. It moved. He stood still. It stood still. He moved, and it moved. He stopped. It stopped. He was terrified. Perhaps it was an animal waiting to pounce... or something else. He yelled loudly, and tears poured down his face. He broke out in a very heavy sweat. No one heard his cries of fear. Tentatively, he moved once more ... and so did that white thing down the trail. After some time he screwed up his courage and dashed toward it. And... (I was so eager to hear) ... and, it was an old undershirt, flapping fitfully in the uncertain breeze. Still, he added, he did wonder at the coincidence of motion and stillness, his and that of the undershirt. Dry chuckles popped from his lips; and, disappointed at what I had hoped would be a breakthrough, I joined in rather weakly.

During these days I met the first of those absent ethnographers. Henry said he was unhappy with the accuracy of some of the materials published about him in an article. I offered to correct these errors. He did not respond. Later I was given to understand, very indirectly, that this was why he had reported his own demise to interested ethnographers; this had been duly recorded in a footnote to a scholarly publication. ${ }^{4}$ Yet I had been informed that he was on the verge of making himself available once more. Why this was so puzzled me greatly; but as yet I had not had any substantive hint that this information was accurate.

After some two weeks of these frequent talks, I gave up. I thought of our conversations as cat-and-mouse routines, and I had come not to doubt which of these was my part. I no longer had any expectations 
of learning from him anything about shamanism or healing. Mulling over the possibilities, I poked around in my rucksack of studentacquired knowledge. Over there, in the corner, under kinship terminology and resting on national character, there was a useful typification: the LIFE HISTORY. Yes, I told myself, I would try to get a life history from Mr. Rupert, that old so-and-so. At least there would be something down on paper about him.

The following day I broached this, and explained what I thought a life history entailed. He would tell me about his childhood, his kin, the jobs he had held, the places he had been, the people he had known, his children. From this we would get a sense of how his life was interwoven with that of his people, and with the recent history of the area. There was no mention of healing nor of power.

During the time I knew him, I saw him agitated twice. This was the first. He exclaimed again that he was just a common man; there was nothing special about him. I retorted that he was special, but did not elaborate. He gave me the Washo term for "healer," which indeed was common knowledge, and added that he had tried "that stuff" a few times, mainly through the use of massage. He gave an example that ended with the statement: "That's suggestion; that's mind power." But, he reiterated, he knew nothing more than these simple things.

We drifted into an unusually lengthy silence. It was a hot and quiet afternoon, dusty with the whiff of a breeze. Looking at him I saw a wizened, still, small, and impassive man. His strong hands rested motionless on his jean-clad thighs, his work boots planted firmly in the dirt. There was no encouragement on that countenance. He had told me that once his mind was made up he never changed it. As time passed, I sensed we were in a sort of null zone of uncertainty and decision, and asked myself whether we ever would get down to the hard facts of the life history. At one point he looked into my face and quietly said, "Stop dreaming."6 Once more he sank into silence. After many minutes, perhaps twenty or twenty-five, he spoke without any preamble: "My life has always been concerned with psychology. I was never a happy-go-lucky man like other Indians. I was always something of a recluse. I always tried to follow the laws of nature...."

I was astounded. This moment was the severest shock I have experienced as an anthropologist, until then and since. I was jolted out of my academic typifications, out of the conceit that I had any entitlement to a privileged vantage point on the lives of others, out of the 
idea that I had any authoritative imprimatur on the creation of knowledge, out of the Other as object.

In retrospect, I thought that I understood what had happened, although we never spoke of this. ${ }^{7}$ In my perception of reality I had replaced the ethnographic category of shamanism with that of life history, believing that in doing so I would leave the former behind, in my reality and in his. In other words, I had been thinking that these textual typifications bore a simple relationship of correspondence to the lived-in and lived-through reality of that Other, out there. Of course, I had done quite the contrary, for I had not understood that in the perceptions, the beliefs and feelings, of this man there was no sphere of living, of being a sentient human being, that was divorced from what he was in essence-a man of power. This was his "culture" (a term I found to have less and less utility). In a roundabout way I inadvertently had forced the issue, but the decision was his.

And into what was I jolted? Into simple yet profound intuitions: that whatever I would say and do would affect his response, and vice-versa; that I could reach out to him only on his own terms, and, therefore, always would be, in a sense, on personal trial (or "walking on eggshells," as I put it then); that I had few rights and many obligations, of which I still was ignorant (and remained so, in large measure, to my cost); that, for the duration of that summer, my own sense of self would become dependent on that Other for sustenance, and, therefore, that he controlled me as none of my academic instructors ever had or would. ${ }^{8}$

This dependency was one reason why I so sorely missed the presence, in their own texts, of those other ethnographers who had talked with him in the past. I needed the perspectives of others like me, with some of my interests, to help me to learn, even if only by contrast, something more of whom I was talking to-how they had felt toward him, whether they had succumbed to the problems they had encountered. But the spirit of such concerns was absent from their writings. The other reason I felt their absence from their own texts was that, from time to time, he made them present; and then I realized acutely my ignorance of what their past presence there had signified.

\section{Kilroy Was Here: The Absent Ethnographer}

Henry's concern for detail was acute: in responding, describing, reminiscing, philosophizing. The very act of following correct proce- 
dures in living and in healing was pervaded with significance and power. Therefore, utterances about various activities had to be accurate. These were not, for him, representations of what he thought and did - the act of talking of them was akin to thinking of them, and so of carrying them through, in a sense, of bringing them into being. Especially, talking of his healing was of danger to him, or to his abilities, and he made this clear at the outset. He had a passion for secrecy in knowledge, knowledge in secrecy; yet, he said that he could teach all he knew to someone else in a brief period-if that person were the right one. But, he added, "People are not supposed to ask me questions about my work. One guy came to see me for help and asked me all kinds of questions-he put me backwards in my work." He remarked on another occasion, "What puts me backwards in my work is someone comes to me for help and asks me a lot of questions about what I can do." And about another inquisitive character, he said "He asked me questions like you are doing, and I told him, "That which is and that which isn't.' He never understood that."

Ethnographers asked him questions about the paranatural, about healing, and he puzzled us with wit and irony that shut topics of discourse just as they opened. Or such was my experience. These qualities of interaction are brought out, for example, in the following brief couplets of talk from my first meetings with him.

D.H.: I've heard that there are Washo who can control the weather [which he was reported to do]. Did you ever come across anything like that?

H.R.: If there was, wouldn't it be raining now?

D.H.: Your friend Ike Steel told me there were Washo, hunters, who could control animals, put them to sleep. Did you ever hear about such Washo?

H.R.: Fool thing! If they could, would they go hungry most of the year?

D.H.: I've been told here that the Spirit World is just like this one.

H.R.: (chuckling): Well, if that's so it must be getting pretty crowded there now.

"He asked me questions like you are doing," said Henry. Over the weeks I learned that this seemed to be the primary role that absent ethnographers played in our conversations. He inserted them contextually, and they became his mouthpieces, responding to my queries. He appeared to introduce them-characters who together with 
me belonged to the same category-to let me see how I looked to him. They were hardly constant companions, for their appearances were intermittent. But they were present, sudden visitations of whom I knew next to nothing, whom I could not grasp to make sense of him, for they had concealed themselves in their texts and so they belonged wholly to him. One appeared, for example, in the midst of a knotty metaphysical tangle that had me confused and skeptical. Henry told of explaining a similar point decades before to an ethnographer. That person had retorted, perhaps offhandedly, perhaps as a challenge to further exegesis, with an abrupt, "I don't believe you." Henry did not conceal from me how much this remark had rankled; and I was warned, via this absent Other, about my attitude. ${ }^{9}$

For Henry Rupert knowledge was experience. When I pushed him to speculate on matters he had not known firsthand, an absent ethnographer might enter the shady space where we talked. So, for example, on the subject of peyote: Henry was a vehement anti-peyotist who insisted that the substance poisoned mind and body, and who cited the experiences of a sister to that effect. When I pressed him further, he responded: "I don't know what peyote is or what its like. That fella from Berkeley asked me about it. I told him I had no opinion. He said I must have some opinion. I asked him how could I have an opinion if I never tried it. After I told him all this stuff, he said it was all just psychology. That's what he said, but after fifty years I haven't figured it all out yet." He followed these remarks with a favorite aphorism of one of his spirit-helpers: "What pertaineth unto one, another knoweth not."

I particularly wanted to watch him heal, and asked about this. Another ethnographer appeared. Henry commented that about a decade before he had allowed an anthropologist to observe a session of healing. The treatment had no effect, for the condition of the patient remained the same. Worse still, Henry could not "see": he did not experience the visions of diagnosis and prognosis upon which his techniques of healing had depended at that time. Since then, he added, no uninvolved or casual observers were permitted; and he quoted an injunction of a spirit helper: "If people just come to you for curiosity, to see how you work, your powers won't work."

When an ethnographer did insert himself into his own text, I suddenly and startlingly saw how Henry Rupert appeared to someone else. I had another perspective, points of overlap and argument, and someone with whom to compare my own perceptions-a sense, how- 
ever brief, of another who momentarily put off center the hegemony of the native presence. One man did this, and although our points of view differed radically, I was grateful for his presence. He wrote:

This man, Henry Rupert ... when questioned about the old days, was a fair informant, seldom offering more information than was asked for and clearly enjoying the business of making a white man work for every scrap of information. He was also given to dropping subtle hints and waiting with stolid indifference to see if I had been alert. He did not deny his shamanistic practices but was less than willing to discuss them in detail. "I don't really do nothing but help nature," he said. When I replied that only some people know how to help nature he was gratified and smiled. "Oh well, it all psychological anyway," he answered, confirming Lowie's description of him as a sophisticate. (Downs 1961: 369)

Where Henry Rupert dwelled I stumbled over memories of other ethnographers when I least expected their presence. It was not simply that they were there before me, and that they had affected or altered the "field" in some way. For they had become embedded in his province of meaning; and I believe that they, or we as a category, may have come to have some particular significance for him. But what I wish to stress here is that of these others, of their contacts with him, I had to learn from Henry Rupert in bits and pieces. To invert a conventional version of discourse among ethnographers, these people were his construction: he embued them with a certain significance, and he mediated any potential or imaginary discourse I might have with them. Just as he edited information about himself (and the evidence of this is clear), so he edited those others into and out of our conversations.

Their absence from their own texts, as engaged persons in relation to him as a person, gave him the uncontested power to dominate their presence in a context (that of fieldwork) that influenced any text I might produce, and that magnified my dependency on him. Therefore, he was the pivot of any discourse about himself, and they in large measure were his creations. And the more they absented themselves from their texts, the more this was so. I believe that this irony was not lost on him. His comments on the multiplicity, and at times, the duplicity, of reality referred specifically to his own perceptions and beliefs ("What I know is real for me, but it's not real for anybody else"; "You don't know what I am talking about, and the same is for anybody 
who reads this thing you write"). But intersubjectivity, he seemed to be saying, is limited by the visions of those who are joined through it.

Their absence, and later my own, from the texts that were produced, the stance of an objectivist ethnography, made of him an object of attention, a member of various typifications ("Washo," "shaman," "remembrancer of the Old Days," and so forth), that invited an absence of comprehension of who and what he was. The ethnographer's interest was what he or she could tell about what Henry Rupert represented as a bearer of our construction of "culture." Henry's performance of self was of little interest, for this was reduced to a signifier of "culture," and then was subsumed in reifications of "culture," and signified in turn by these. So it is not surprising that these texts either missed, excluded, or downgraded that which I came to see as outstanding in him-that he was a most creative individual, one who radically changed his own epistemology of belief in ways that had practical and substantive effects on his healing (Handelman 1967a, 1967b). ${ }^{10}$

I came away from that relationship with an ingenuous question that was absent from all of our texts. Why, after all, did he talk to any of us? There were some hints. But with the years and the aid of seminars and publications, I turned him back into an object of inquiry, and so I did not see perhaps one of the most apparent of interpretations. Not until, that is, I came across that fragment of Grace Dangberg's writing to which I have alluded. This reads in part as follows: ${ }^{11}$

Across the table from me sat the man who had acted as interpreter for me over a period of several months during which we had reached a rapport that gave promise of making me the confidant of a Washoe Indian medecine man or shaman. In the months when I had done fieldwork with this tribe I never even hoped that there might come a time when I . . . would be privileged to hear one who was a practicing medecine man tell of his intimate experiences in the world of religion and magic. Henry's eyes were very bright. They were fastened on me with quiet intensity and amused tolerance. He was willing to talk and as I review this day in my memory I feel that like Kim's holy man he was seeking a disciple. His experiences were not the private property of a magician-they were manifestations of power-a power that pervades the universe. He wanted others to share these impressive mysteries with him - to understand them-to speak of them to all men.

This was in the early 1920s. I kept my notes speculating what I might do with them one day when Henry could not be hurt by my giving an account of what he had confided in me. In this attitude, I am sure I 
erred. Henry wanted me to "tell the news" as it were and here in my narrow understanding of the significance of his revelation I failed him. Of this I became aware when a young student published a paper on the last of the Washoe medecine men or shamans. This was Henry whose full name is Henry Moses Rupert.

Today I believe that Grace Dangberg's intuition was correct. He was looking for a successor. Conversing with him in 1964, enchanted perhaps by my dependency, perhaps by what I felt was his essence, I had had similar feelings. Little by little these had eroded and become less poignant, as I wrote of him and made of him a character who served my purpose. Bound by injunctions of humility and secrecy, he had to proceed with care and with caution in checking possible candidates against the personal and ethical guidelines that his spirit helpers had stipulated for the passing on of his knowledge (Handelman 1972). Ethnographers were not excluded as candidates. No person was. The practice of his own theory of healing was universal. Ironically, ethnographers may have been among those persons who showed the most consistent interest in learning of his thoughts and doings. Given the social conditions that prevailed there, at least until the later 1960s, this may well have been the case.

Today I like to think of him, reclusive and self-contained, patiently waiting at the edge of the desert for the right person, checking us off one by one as we intermittently passed through, intent on our own doings - an image of humor and irony. For he and we may well have had goals that overlapped: yet, by making of him the sort of typification to which I have alluded, we subverted the further acquisition of knowledge that was, after all, the point of our efforts. It will not surprise those of you who have read my previous accounts of Henry that he found a solution to the passing on of certain of his talents before he died-one that was as unorthodox as the life he lived.

\section{Who's in Here? Our Absence from One Another's Texts}

I first wrote parts of this section with tongue in cheek, as a parody of those of us who are infatuated with the reflexive genre of anthropological writing - sometimes to the point of making the individual ethnographer the rationale for ethnography, while reducing natives to props for self-preoccupation, and social order to an extension of the ethnog- 
rapher's psyche. Ethnography as cosmic creation or navel-gazing? Perhaps some gentle joshing . . . but this became irrelevant when readers took these arguments seriously. On second look, so do I.

The struggle over the voice of the native Other is in part one over the (often dialogical) contributions that these others have made to the construction of the text. But what of our own contributions to the textual constructions of one another? Surely we have similar obligations to these Others as we have to the native? All of us converse with, listen to, and read others of our kind. There is no doubt that we influence one another's thinking and writing. Few ideas, or their denial, spring pristine from our minds to the written page; and I would subject to the most minute scrutiny those who claim otherwise. If our concern is with influences on textual construction, then we should render an accounting of all Others who are imprisoned in the text, and the degrees of freedom permitted them. For they are all representations, and misrepresentations, of active voices, of authorships that are stilled and pacified by the formal logics of textual construction. However, to pursue the logic of the voice of the Other in our texts is quickly to breach and to expose the systematic constraints and occupational fictions that underwrite and sustain our endeavors, and, therefore, that need to be blocked from view in scholarly debate.

It is an error of our epistemology to continue to evaluate the making of a place for the voice of the Other in ethnographic texts as a problem primarily of reflexivity, aesthetics, science, or ethics. The problem of the voice of the Other is conditioned by more elementary cultural ideas of "career" and of proprietary rights to knowledge and expertise. ${ }^{12}$ These ideas (and others that relate to academic production) are problems of the means of cultural production that underlie and inform the continuum of Other voices, from the native's to other ethnographers'. Should the voice of the Other seem more immanent in the ethnographer-native relationship than in that between ethnographers ${ }^{13}$ then this is a product of our conventions of presentation and not of the dialogic of interchange. The radical opening up of the text to the voice of the native Other has addressed the simpler end of the continuum, one that does not depend for its very coherence on institutional infrastructures, from universities to publishing companies.

The "career" of the ethnographer is necessarily an individualist construct. Whatever the factors that go into its making, the career is thought of as owned by the individual ethnographer. It represents to others what he or she is in a professional and occupational sense; 
therefore, it is a reflection and an index of his or her ideas, stature, and recognition. "Discourses," writes Foucault (1979: 148), "are objects of appropriation." The cooptation of discourse is one of the signal assets of the career of the ethnographer and is often a source of knowledge, of expertise, and of the production of texts under his or her name. In turn, these texts are thought to reflect the ethnographer's knowledge and expertise. One of the major sources of knowledge and expertise is the mind and action of the Other-access is gained through the informants, subjects, confidants, with whom one talks and at whom one looks. The products of these discourses are the commodities of the ethnographer's career; in varying degrees, he or she claims proprietary rights over them for professional purposes. Informally the ethnographer may lay claim as well to the sources of such discourse. Without these commodities, identified with his or her name, the ethnographer would be largely anonymous, and so unable to pursue a career. ${ }^{14}$

To ask us to cease treating native voices in the texts as commodities would require adjustments in the work, mainly, of the individual ethnographer. But to pursue this logic of Other voices in the text, to ask that we stop treating one another as commodities would demand far-reaching changes in our discipline, and in the institutions whose resources and decisions shape our professional lives. These institutions often control the signifiers of our accomplishments, of publication and promotion, for example. They demand our professional individuation, our formal separation from one another, in order to make these accomplishments significant. Therefore, the voices in the text, ours and others, must be ordered hierarchically to leave little doubt as to whose creation this is.

To continue to divide relationships in the "field" from those at "home" is to encourage the survival of the false dichotomy between the aesthetics of text construction, on the one hand, and the political economy of careers on the other. And the decolonization of the voice of the native Other will proceed apace at the expense of our continued colonization of one another's voices.

Let me take this argument one step further by looking at the simple organization and packaging of the scholarly book or monograph. The emphasis on hierarchy in its structuring accords well with ideas of the proprietorship or copyright of knowledge, and of our subordination of one another's voices. The monograph-a signal accomplishment of the 
career-reflects and extends the domination of the individual ethnographer, perhaps even while proclaiming the need for the dialogic.

The structuring of the book (Barry Schwartz's Vertical Classification is metonymic with this argument) is quite in accord with Whitehead and Russell's Theory of Logical Types. The book is put together through principles of hierarchy, of encompassment, of lineal progression, and —of course - of vertical classification.

The overall space of the book is produced and usually is owned by a publisher. The publisher encompasses the book. The book encompasses whatever is within it. Most of its outside space, the borders that separate it from entities of the same and other classes of phenomena, is called the "cover." As befits boundaries, the cover is of a different weight, thickness, and constitution than the interior of the book. Part of the cover is occupied by the name of the book. It is a particular named entity. The name of the book also may have another name. In this instance the other name is subordinate to the principal name and is called a "subtitle" (viz. Vertical Classification: A Study in Structuralism and the Sociology of Knowledge). In such a case, the title usually is more abstract (or poetic) and the subtitle more specific (or factual). ${ }^{15}$

A named book has an author or an editor who usually is a specific person. Yet, note that although it is possible for a named book to exist without an author (viz., anonymous), it is much more difficult for an author to publish a book without a name. (Think of the paradoxes of classification thereby generated.) The author is responsible for the text contained within the covers of the book. The author encompasses the text. The text is subordinate to the author; the author is subordinate to the named entity of the book, in its independent, printed existence; the book is subordinate to the publisher.

The text proceeds according to a lineal logic: title page, table of contents, chapters numbered from I to $\mathrm{n}$, pages numbered from 1 to $n$. Chapter I is an introduction of some sort that signifies its function of beginning and contextualizing. The final chapter is a conclusion of some sort that signifies its function of closing and contextualizing. If the book is thought to be well organized, each successive chapter will depend for its coherence and comprehensibility, to a degree, on the chapters that precede it.

In other words, the entire structuring of the book signifies and oversignifies encompassment, hierarchy, and subordination; the more gen- 
eral and the more particular rarely are confounded. These texts are logical exercises in the suppression of paradoxicality that is produced by the confusion of levels of abstraction, by the erasure of borders.

Within this structure are located the conventions that are used by the author to insert the voices of other ethnographers: in the ritualized offering of Acknowledgments (where the thanks may be profuse, but where the author takes all responsibility); imprisoned within quotation marks (where for a few sentences our words can be used without our consent, and in relation to which we often complain of being quoted "out of context"); locked in parentheses as citations; and plunked into footnotes and appendices as annotations and addenda to the principal text. The use of different typefaces, indentations, and so forth all attest to our presence as deviant (and so, subordinate) to the norms of the text. At best these are subtexts-again in the language of hierarchy and domination. These conventions no more allow for the voice of an authentic, ethnographic Other than they do for that of the native.

We live and experience these constructions and conventions, and accept their necessity in order to get on with our work, to get this published, and to be accorded proper authorship for that. Perhaps this is why we are less reflective about the implications of this ordering of the text. We endlessly protest our concerns for the culture of the native Other. But such texts are artifacts of our own culture; and to these, on the whole, we remain blind. For I read of no cries of anguish over our colonization, as object, of one another's voices. But, reflective or not, I am stressing that the tyrannies of the text derive from a textual construction whose very logic of organization is that of domination and subordination-a machine for the appropriation of discourse that is compatible with our ideas of authorship and proprietorship of knowledge.

Short of a revolution, one that likely is technological as well as epistemological, and one whose parameters may require alternatives to writing, I cannot see doing away with the tyrannies of Logical Typing that are embedded in the finished product of the ethnographic text. In this regard, as stimulating as they may be, the dialogical and the polyphonic are but pretty streamers of aesthetic protest that reaffirm the authority of hierarchy and encompassment; but they also conceal our textual domination of one another within a fiction-that the center of our work lies "out there," and not also "in here" where we dwell, embedded ourselves in institutional and professional constraints.

On the other hand, I have expounded another fiction here, one that 
we live with quite comfortably: that the finished text is isomorphic with its construction, and that it does indeed embody what our endeavors are about. But, after all, we know that our finished texts have only a limited relationship to how they actually were put together.

\section{Afterword-To the Editors}

You asked whether I could bring Henry Rupert back in at the end of this essay, perhaps to relate how his insights helped me to realize the hegemony of textual conventions. I procrastinated for a long time, because I was struck by the utter reasonableness of the request. It suggested the following line of thinking: Henry, in large measure, awoke me to the significance of the Other as subject, although I used other terms at the time. In counterpoint to the absence of native Others in textual representation, I was led to think about ethnographers' absence from one another's texts. Therefore, should not Henry's insights, and their impact on me, be related to my own thoughts on our textual domination of one another?

The logical coherence of this chain of thought belies its seductive powers and indirectly illustrates my contentions about the tyrannies of the text-that is why I cannot accede to the request. Convention: an ethnographic text should be synthetic, demonstrating logical development and coherence, seamlessly building on itself toward some sense of climax, its loose ends safely knotted or tucked away. The conclusion, the climax, finally integrates the text, closes it off, reflects on this, and transcends it. This is the end of the text and the end of the story that makes the text a proper story. Above all, this structure is aesthetically pleasing. It reads right, feels right-a job completed, cast into the world to make its way. Good enough to be independent of its author.

And, in this instance, it also is sheer poetism, to which we accede conventionally all too often. Poetism? A theory or presentation whose only claim for consideration is that it is aesthetically pleasing. If Henry Rupert influenced the way I see a book as the hegemony of textual conventions, I am unaware of this. It would be aesthetically pleasing to the organization of this paper if I wrote that it were so. It is not. Henry belongs to the parts in which he appears, and not to the others.

But I am saddened. It is not what $I$ intended at the outset. He was to be the focus throughout. I am saddened that I could write him so 
easily out of the text when he no longer fit, or had served my purpose. So here there only are loose ends that dangle sensuously in my memory of him, uncommitted and uncommitable to paper. In the beginning I wanted to tell you, Listen, listen to how much this man means to me. Now I'm no longer sure if it is the man or the symbol.

\section{Notes}

1. In aboriginal times the Washo were a hunting and gathering people, small in number, who wintered in the valleys of the west-central Great Basin and who spent their summers in the Sierra Nevada mountains and on the eastern shores of Lake Tahoe. Overviews of reconstructions of aboriginal Washo culture are found in d'Azevedo 1963. The most comprehensive overview of Washo shamanism during the modern period is that of Siskin 1983.

2. And by this I mean inlaid in the text itself, so that its proprietorship becomes blurred, and not in a subtext, for instance an appendix (cf. Bruner and Gorfain 1984), or by way of comments as in the early Current Anthropology.

3. This was not my first fieldwork. I had passed half a year studying the adaptations of West Indian migrants to a large Canadian city.

4. "Since we made our last field trip to the Washo Indians in 1956-57, we have learned that this shaman has died" (Freed and Freed 1963: 39).

5. He already had told me of how he learned hypnotism from a mail-order book (Handelman 1967a); and I did not attribute any special significance to this statement.

6 . The implications of this utterance are profound, given the significance of dream or vision to the novice healer, and, more generally, in communication with the paranatural (Handelman 1967a, 1972). During those minutes I did not realize this.

7. A month later he stopped speaking, just as abruptly, about these subjects. $\mathrm{He}$ explained that a spirit helper had warned him of the adverse effects of our conversations on his healing. We talked of other matters, but, with a single exception, never returned to that of power.

8. When I moved on to different work, he remained for me very much a teacher, and this was how I remembered him (Handelman 1977: xiv).

9. Some years later I asked the ethnographer in question about this incident, but he remembered nothing of it.

10. Some twenty-five years ago I submitted a manuscript about Henry Rupert to Ethnology. It was entitled "Creativity in Culture Change." The bulk of the manuscript was constituted of lengthy quotations of Henry's words, from my fieldnotes, articulated by my own commentaries and interpretations. At the time I had never heard of questions of textual construction, nor, for that matter, of exegesis. I did feel that he could represent himself better (in relation to the subject of the paper) than I could do this for him. Nonetheless, I still am certain that the choice of problem and the mode of its presentation are largely the prerogatives of the ethnographer-author. The editor, G.P. Murdock (who was also my teacher at the time), rejected the title on the grounds that "creativity," with its implications for the creative individual, was not a suitable topic for ethnographic inquiry rooted in the study of culture. Moreover, he rejected the format of the paper because it was not scientific. Today, I think he was disturbed by the extent to which my informant had come to dominate the text. 
11. Quoted with the permission of Grace Dangberg, from her unpublished fieldnotes. Personal communication, 10 January 1985.

12. The most comprehensive overview to date (Marcus and Cushman 1982) discusses, in various terms, the cultural (ethnographic) production of texts, but does not even mention the significance of their cultural (institutional, occupational) means of production. The distinction of "work in the field" and "work at home" continues to be sustained, such that the major intersection of these spheres is through the medium of the individual ethnographer. This mystification of the reality of work continues to pervade ethnography. Aspects of my critique in this essay are continued in Handelman 1994.

13. Smadar Lavie pointed this out to me.

14. Clearly, proprietorship over the authorship of textual production is not universal. Writing of Bengali jatra playwrights, Farber (Sequin and Farber 1978: 343) notes that "while they are paid to write plays and while they relinquish claims over them, [they] do not keep copies of their plays, do not expect to be cited when the play is either rewritten or sold for 'movie or performance' rights, do not remember the titles they attribute to their plays, and do not assert the right to control the deployment of their literary energies." Farber attributes these characteristics of authorship to Bengali conceptions that creative energy is part of cosmic energy that cannot be owned but merely possessed or shared.

15. As, for example, in these titles plucked from my bookshelves-Day of Shining Red: An Essay on Understanding Ritual, or Reality in a Looking-Glass: Rationality through an Analysis of Traditional Folly.

\section{REFERENCES}

Bruner, Edward M., and Phyllis Gorfain. 1984 "Dialogic Narration and the Paradoxes of Masada." In Edward M. Bruner, ed., Text, Play, and Story: The Construction and Reconstruction of Self and Society. Washington, D.C.: 1983 Proceedings of the American Ethnological Society. Pp. 56-79.

Clifford, James. 1983. “On Ethnographic Authority." Representations 1: 118-46. d'Azevedo, Warren L., ed. 1963. The Washo Indians of California and Nevada. Salt Lake City: University of Utah Anthropological Papers, no. 67.

Downs, James F. 1961. "Washo Religion." Anthropological Records 16: 365-85.

Dwyer, Kevin. 1982. Moroccan Dialogues: Anthropology in Question. Baltimore: Johns Hopkins University Press.

Foucault, Michel. 1979. "What Is an Author?” In Josué V. Harari, ed., Textual Strategies: Perspectives in Post-Structural Criticism. Ithaca: Cornell University Press. Pp. 141-60.

Freed, Stanley A., and Ruth S. Freed. 1963. "The Persistence of Aboriginal Ceremonies among the Washo Indians." In Warren L. d'Azevedo, ed., The Washo Indians of California and Nevada. Salt Lake City: University of Utah Anthropological Papers, no. 67. Pp. 25-40.

Handelman, Don. 1967a. "The Development of a Washo Shaman." Ethnology 6: 444-64. 


\section{Don Handelman}

1967b. “Transcultural Shamanic Healing: a Washo Example." Ethnos 32: 149-66.

- 1972. "Aspects of the Moral Compact of a Washo Shaman." Anthropological Quarterly 45: 84-101.

- 1977. Work and Play among the Aged: Interaction, Replication, and Emergence in a Jerusalem Setting. Assen/Amsterdam: Van Gorcum.

. 1994. "Critiques of Anthropology: Literary Turns, Slippery Bends." Poetics Today, forthcoming.

Little, Kenneth. 1980. "Explanation and Individual Lives: A Recognition of Life Writing in Anthropology." Dialectical Anthropology 5: 215-26.

Marcus, George E., and Dick Cushman. 1982. "Ethnographies as Texts." Annual Review of Anthropology 11: 25-69.

Pandey, Triloki Nath. 1972. "Anthropologists at Zuni." Proceedings of the American Philosophical Society 116: 321-37.

Seguin, Margaret, and Carole Farber. 1978. "Whose Who's": Possession and Ownership in Hindi and Bengali." In Richard Preston, ed., Papers From the 4th Annual Congress (CES). Ottawa: National Museum of Man Mercury Series. Pp. 337-44.

Siskin, Edgar E. 1983. Washo Shamans and Peyotists: Religious Conflict in an American Indian Tribe. Salt Lake City: University of Utah Press.

Tedlock, Dennis. 1979. "The Analogical Tradition and the Emergence of a Dialogical Anthropology." Journal of Anthropological Research 35: 387-400. 